\title{
RECENT ARCHÆOLOGICAL EXCAVATIONS IN EGYPT
}

\begin{abstract}
$T$ HE Merimda Civilization. Results of importance for their bearing on stratigraphical relations and development in culture were obtained in the excavations of the Academy of Sciences on the prehistoric site of Merimda-Beni Salama, west of the Nile Delta, which lasted from January 25 until April 4, 1939. In this season-the seventh devoted to this site-it has been demonstrated that of the various levels each corresponds to a different stage of development, contrary to the earlier conclusion that the Merimda civilization was uniform throughout. Although, it is true, the population did not change, and the mode of life throughout was the same-the practice of agriculture, combined with stock-breeding and huntingwhile their weapons and tools wero similar, and their burial customs identical, yet it is now possible to trace development.
\end{abstract}

Three levels of occupation can be distinguished. The first is a wide stretch of sand, yellowish in colour, on which the inhabitants lived in lightly constructed huts, too widely spaced to prevent the invasion of the sand, in which the hearths aro visible in black, while the interments are shown by groyish tints. The second level is of a light grey colour, showing a series of superimposed surfaces, hardened by occupa. tion. The constructions were closer together, and of a more solid character. The third layer is of a deep blackish colour, consisting in the main of the debris of human habitation, in which the proportion of sand is very much less than in the earlier levels. The settlement evidently was a much closer agglomeration of structures, oval in shape and constructed of lumps of clay, which make their appearance for the first time together with large baskets for cereals. These baskets were buried in the earth, and are replaced later by large pottery jars. The evidence shows a development from a scattered occupation to a compact town, traversed by streets.

It has now been established that numerous types of pottery found in the primitive settlement are perpetuated throughout the whole duration of occupation, but that others disappear in the course of development. Such, for example, is the fate of fine basins of a hard clayey material, with a brilliant red polish on the exterior, except for an unpolished horizontal band engraved with a palm-leaf motif. This is found more rarely and of inferior quality in the second layer, and disappears, and with it the palm-leaf motif, in the third. Next season's work will be dovoted to working out further evidence of development on these lines.

Saqqara. During the last two or three seasons, the excavations by the Antiquities Department of the Step Pyramid at Saqqara have been intermitted in the interests of clearance and preservation. In the past season, MI. Lauer has been engaged in clearing the great court, measuring $180 \mathrm{~m}$. by $100 \mathrm{~m}$., at the south of the pyramid. The clearance resulted in the discovery of fasciculated column drums of the colonnade in process of being restored, portions of boundary stones inscribed with the names of Zoser and the princesses Hetep-her-nebti and Int-ka-s, and a small fragment of the statue of Zoser with the titles of Im-hotep belonging to the statuo found twelve years ago.

Among other finds were three little granite statuettes of the Fifth Dynasty, which had been stolen by robbers but abandoned. Two of them represent the same person standing. They bear traces of colour on the head, the eyobrows, the eyes, and the nails, the granite representing the skin. The clothing was also painted. The third statuette of black granite also bears traces of colour, and is inscribed with the namo of Her-en-kaw, director of the scribes of the textile fabrics. A head of a woman in stuccoed and painted wood found near by, which seems to date from the New Kingdom, shows a pair of earrings which are painted black.

Before the close of the season, the clearance was completed of the south side of the Pyramid of Unas and of the contour of his funerary temple. Evidence was then brought to light that Unas, in order to build his own pyramid, had completely destroyed the funerary monument of his predecessor Dadkare. This action, taken in conjunction with the evidence of certain inscribed material, found in the course of the work, raises the important historical point as to the identity of the ruler responsible for the change of dynasty usually attributed to Teti. To this question no answer can yet bo given.

Tuna el Gebal (Hermopolis West). Excavations on this site by the Fouad I University, which last season had been occupied with material of the Ptolemaic period, were again pushed forward in Gallery $C$, and by the end of the season had reached the period of Psammetichus and Amasis. On clearing the gallery, an interior room cut below it appeared. Here, in a further chamber, a remarkable discovery was that of a sarcophagus. Previous evidence suggested that these galleries had been reserved for the mummies of ibises and baboons; but the sarcophagus proved to be that of a prince and chief priest of Hermopolis. The chamber was filled with canopic jars of alabaster, covered with inscriptions, and placed in pairs on either side of the sarcophagus. Their covers were carefully sculptured with the heads of the four "Sons of Horus". At the right of the sarcophagus at the foot were 400 blue faience statuettes (ushabtis) inscribed with the name of the high-priest Ankh-hor; while on the east side were several blue faienco vases containing unguents, fruits, and gilded leaves. Tho sarcophagus contained a mummiform coffin of wood. The mummy wore a mask of silver and a band of gilt leather on the chest. On both sides of the body were two sheets of gilt bronze bearing in relief figures of the four "Sons of Horus". The mummy lay with head to west.

Another corridor filled with jars which, apparently, had not been reached by robbers, yielded 125 statuettes of Osiris in bronze, statuettes of isis, and of the bull, while among the finest pieces was a prince of Hermopolis standing between the goddesses Isis and Nephthys with Horus in front of him on a lotus column, flanked by the two uraei of Upper and Lower Egypt. This ensemble is before an Ibis seated on a stand, sculptured and set with stones of many colours imitating lotus flowers. 